\title{
Analisis Video Comments to Subscribe Ratio Youtube Pada 5 Artis Terkaya di Indonesia
}

\author{
Ni Putu Rika Sintiadewi (19101007) \\ STIMIK STIKOM Indonesia \\ rikasintia04@gmail.com
}

\begin{abstract}
ABSTRAK
Youtube is a video sharing website created by three former PayPal employees in February 2005. This website allows users to upload, watch and share videos. The company is headquartered in San Bruno, California, and uses Adobe Flash Video and HTML5 technologies to display a wide variety of user/creator-generated video content, including movie clips, TV clips, and music videos. In addition, amateur content such as video blogs, short original videos, and educational videos are also available on this site. Most content on YouTube is uploaded by individuals, although media companies such as CBS, BBC, Vevo, Hulu, and other organizations already upload their material to the site as part of the YouTube partnership programme. Unregistered users can watch videos, while registered users can upload an unlimited number of videos. Videos deemed to contain offensive content can only be watched by registered users aged 18 years or over. In November 2006, YouTube, LLC was purchased by Google for US\$1.65 billion and officially operates as a subsidiary of Google. Youtube was founded February 14, 200516 years ago.
\end{abstract}

Youtube, which is active in Indonesia, can certainly provide opportunities for the richest youtubers to make the Youtube platform a social media marketing platform. The 5 richest Youtubers in Indonesia who use Youtube accounts as a marketing platform, namely: Dedy Corbuzer, Rans Entertainment, Baim Paula, Atta Halilintar, Ria Ricis. The purpose of this study is to calculate the credibility of the Youtube account performance of the Top 5 Youtubers in Indonesia. The method used for this research is quantitative exploratory method. The results of this study indicate that the Baim Paula Youtuber account in Indonesia is ranked first and has good account performance credibility. 


\section{ABSTRAK}

Youtube adalah sebuah situs web berbagi video yang dibuat oleh tiga mantan karyawan PayPal pada Februari 2005. Situs web ini memungkinkan pengguna mengunggah, menonton, dan berbagi video. Perusahaan ini berkantor pusat di San Bruno, California, dan memakai teknologi Adobe Flash Video dan HTML5 untuk menampilkan berbagai macam konten video buatan pengguna/kreator, termasuk klip film, klip TV, dan video musik. Selain itu, konten amatir seperti blog video, video orisinal pendek, dan video pendidikan juga ada dalam situs ini. Kebanyakan konten di YouTube diunggah oleh individu, meskipun perusahaanperusahaan media seperti CBS, BBC, Vevo, Hulu, dan organisasi lain sudah mengunggah material mereka ke situs ini sebagai bagian dari program kemitraan YouTube(Wikipedia bahasa Indonesia, 2020). Pengguna tak terdaftar dapat menonton video, sementara pengguna terdaftar dapat mengunggah video dalam jumlah tak terbatas. Video-video yang dianggap berisi konten ofensif hanya bisa ditonton oleh pengguna terdaftar berusia 18 tahun atau lebih. Pada November 2006, YouTube, LLC dibeli oleh Google dengan nilai US\$1,65 miliar dan resmi beroperasi sebagai anak perusahaan Google. Youtube didirikan 14 Februari 200516 tahun lalu.

Youtube yang aktif di Indonesia tentu dapat memberikan peluang bagi para youtuber terkaya untuk menjadikan platform Youtube sebagai platform social media marketing. Adapun 5 Youtuber terkaya di Indonesia yang memanfaatkan akun Youtube sebagai platform marketing, yaitu : Dedy Corbuzer, Rans Entertaiment, Baim Paula, Atta Halilintar, Ria Ricis. Tujuan dari penelitian ini yaitu untuk menghitung kredibilitas dari performa akun Youtube Top 5 Youtubeer di Indonesia. Metode yang digunakan untuk penelitian ini yaitu metode eksploratif kuantitatif. Hasil dari penelitian ini menunjukan bahwa akun Youtuber Baim Paula di Indonesia mendapatkan peringkat pertama dan memiliki kredibilitas performa akun yang baik.

Keyword : Credibility Account Youtube Social Media Marketing Social Media Youtube Video Comments to Subscribe Ratio Youtube di Indonesia. 


\section{PENDAhuluan}

Teknologi informasi dan komunikasi yang telah berkembang dengan pesat mampu menghantarkan manusia untuk menciptakan bentuk baru dalam cara berkomunikasi serta berinteraksi melalui media sosial. Media sosial memberikan pengaruh yang cukup besar, saat ini media sosial diajadikan sarana berkomunikasi dalam setiap aktifitas keseharian bersosial di masyarakat. Komunikasi tidak hanya dapat dilakukan secara fisik, tetapi juga dapat dilakukan dengan menggunakan berbagai aplikasi media sosial di dunia maya. Keunggulan layanan aplikasi sosial media adalah memberikan ruang komunikasi dua arah antara konsumen perusahaan dan konsumen-konsumen.

Dengan pesatnya perkembangan teknologi media sosial, telah memberikan dampak terhadap situs-situs komunikasi, dari yang awalnya hanya sekedar email dan chatting, saat ini sudah banyak jejaring media sosial yang bisa digunakan sebagai alat komunikasi. Contoh aplikasi sosial media yang memiliki banyak pengguna saat ini yaitu Youtube. Youtube merupakan aplikasi yang diluncurkan oleh perusahaan Google LLC. Youtube memungkinkan penggunanya membuat video bermacam-macam durasi mulai dari 5 menit sampai 1atau 2 jam yang disertai dengan musik, filter, dan beberapa fitur kreatif lainnya(Chandra, 2018).

Kehadiran media sosial Youtube dapat membangun sebuah brand, Youtube juga dapat membangun personal branding pemiliknya. Di Indonesia, terdapat 181,9 juta pengguna Youtube yang aktif sehingga menjadikan Indonesia sebagai negara dengan pengguna TikTok terbesar di dunia. Maraknya jumlah pengguna Youtube aktif di Indonesia tentu dapat memberikan peluang bagi brand untuk menjadikan platform ini sebagai platform sosial media marketing(Wirga, 2016). Cukup banyak akun perushaan-perusahaan terkenal yang ada pada youtube, contohnya seperti youtuber di Indonesia. Adapun Top 5 Youtuber di Indonesia, diantaranya yaitu : Dedy Corbuzer, Rans Entertaiment, Baim Paula, Atta Halilintar, Ria Ricis. 
Penelitian ini menggunakan metode eksploratif kuantitatif, dan akan menghitung menggunakan rasio-rasio yang ada pada Youtube menjelaskan bahwa terdapat 7 rasio yang ada pada sosial media Youtube dan relevan digunakan sebagai media ukur kredibilitas akun yang ada. Penelitian ini hanya berfokus untuk menghitung kredibilitas Video Comments to Subscribe Ratio pada Top 5 Youtuber terkaya di Indonesia. Adapun Top 5 Youtuber terkaya di Indonesia, diantaranya yaitu : Dedy Corbuzer, Rans Entertaiment, Baim Paula, Atta Halilintar, Ria Ricis. Tujuan dari penelitian ini adalah mengetahui kredibilitas performa dari akun Youtube Top 5 Youtuber terkaya di Indonesia menggunakan Video Comments to Subscribe Ratio.

\section{TINJAUAN PUSTAKA}

Perkembangan bidang teknologi saat ini terjadi begitu pesat. Melalui perkembangan yang terjadi dari waktu ke waktu menimbulkan maraknya aplikasi -aplikasi serta platform media sosial yang bermunculan. Aplikasi yang sangat diminati oleh masyarakat saat ini diantaranya adalah TikTok, Instagram, Twitter, WhatsApp dan yang lain sebagainya. Seiring berjalannya waktu, aplikasi sosial media tersebut dapat menjadi candu bagi kalangan masyarakat. Tidak hanya kalangan remaja yang menggunakan aplikasi sosial media, orang tua bahkan anak-anak juga aktif menggunakan aplikasi sosial media tersebut.

Youtube perkembangan terpesat dibandingkan dengan kategori new media yang lainnya seperti facebook, Instagram, tiktok, dan Twitter. Dari sekian banyak aplikasi sosial media, Youtube menjadi aplikasi yang memiliki pengguna aktif terbanyak. Youtube merupakan jejaring sosial media dalam bentuk video yang umumnya yang tersedia berbagai mavam durasi. Pada aplikasi Youtube pengguna dapat menggungah video sesuai dengan kebutuhan, selain itu youtube juga bisa menyimpan video, Selain itu, pengguna dapat membagikan video, dan lain sebagainya. 
Di Indonesia, fenomena anak muda dalam menggunakan Youtube menunjukan antusiasme yang sangat massif. Meraka berlomba membangun identitas demi mendapatkan citra yang diinginkan, seperti dipuji dan dikenal oleh banyak orang . Aplikasi Youtube semakin populer sejak diluncurkan tahun 2005. Bahkan Youtube telah mencetak berbagai macam prestasi.

Aplikasi Youtube tidak hanya digunakan untuk membuat konten video dengan tujuan menghibur pengguna lainnya. Aplikasi Youtube juga dapat dijadikan peluang bagi brand atau perusahaan sebagai platform social media marketing, Youtube dirasakan memiliki kekuatan ataupun pengaruh dalam industri, sehingga menimbulkan kualitas akun yang menentukan strata maupun kredibilitas pemilik akun Kredibilitas akun youtube merupakan suatu hal yang cukup penting untuk berbagai kepentingan. Kredibilitas sebuah akun youtube dapat diukur dari tingkat performa yang dihasilkan secara matematis. Dalam mengukur performa diperlukan skala pengukuran yang tertuang ke dalam rasio.

\section{METODE PENELITIAN}

Penelitian ini menggunakan metode eksploratif kuantitatif untuk mengetahui kredibilitas dari performa akun Youtube di Indonesia. Metode eksploratif merupakan penelitian yang memiliki tujuan untuk melakukan eksplorasi atau memperdalam pengetahuan ataupun ide-ide baru mengenai suatu hal yang baru, guna merumuskan permasalahan secara terperinci .

Tujuan dari penelitian ini yaitu mengetahui nilai kredibillitas dari performa akun Youtube 5 Youtuber. Ada beberapa langkah yang harus dilakukan dalam penelitian ini, sehingga mampu menemukan peringkat pertama akun Youtuber di Indonesia yang memiliki performa terbaik. Langkah-langkah yang dilakukan pada penelitian ini, diantaranya yaitu(Permana \& Kom, n.d.): 


\section{Melakukan Eksplorasi Pada Website Untuk Menentukan Objek yang Akan}

\section{Dianalisa.}

Eksplorasi ini dilakukan pada beberapa halaman website yang menyediakan informasi mengenai objek yang akan di teliti. Setelah ekslorasi selesai dilakukan, sehingga

ditemukan nama-nama youtuber di Indonesia yang akan dijadikan objek analisa. Setelah melakukan eksplorasi pada halaman website, maka langkah selanjutnya yaitu mencari nama akun Youtuber dari masing-masing youtuber. Pastikan semua youtuber memiliki akun pada aplikasi sosial media Youtube.

\section{Menghitung Nilai Rata-Rata Variable Dari Top 5 Youtuber Terkaya di}

\section{Indonesia.}

Pada langkah ini, peneliti menghitung nilai variable video comments dan variable video views. Variabel merupakan sesuatu yang memiliki nilai bervariasi dimana nilai tersebut dapat dijadikan sebagai dasar untuk empat data yang berbeda seperti rasio, skala, ordinal, nominal dan internal. Untuk menghitung nilai rata-rata dari variabel video comments dan variabel video views yaitu dengan cara mengambil minimal 10 postingan kemudian di hitung sehingga menemukan nilai rata-rata dari masing-masing variabel.

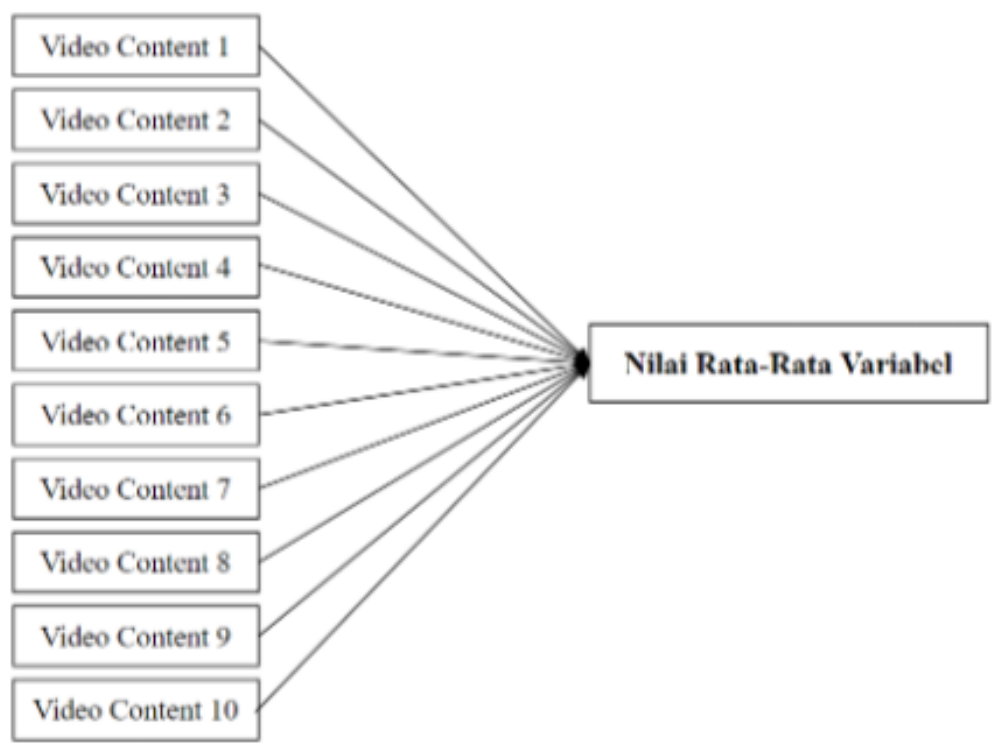

Gambar 1. Analisa Nilai Rata-Rata Variabel. 


\section{Menghitung Nilai Kredibilitas Rasio}

Untuk menghitung nilai kredibilitas dari video comments to video subscribe ratio, peneliti menggunakan cara membagi nilai variabel pertama dengan nilai variabel kedua. Jika video comments memiliki nilai 100 dan video views memiliki nilai 300, maka cara menghitungnya yaitu $100: 300=0,3$. Dengan begitu nilai dari video comments to video subscrib ratio adalah 0,3 .

\section{Menentukan Peringkat Pada Akun Youtuber}

Pada langkah terakhir yang dilakukan pada penelitian ini yaitu menentukan peringkat pada masing-masing rasio yang ada. Pada penentuan peringkat perlu melihat karakteristik dari rasio yang di teliti. Jika karakteristik rasio merupakan rendah, maka objek yang memiliki nilai terendah akan mendapatkan angka 5 dan objek yang memiliki nilai tertinggi akan mendapatkan angka 1 . Namun jika rasio memiliki karakteritik tinggi maka objek yang mendapatkan nilai tinggi akan mendapatkan angka 5 dan objek yang mendapatkan nilai terendah akan mendapatkan angka 1. Setelah mendapatkan hasil kredibilitas ratio maka dapat disimpulkan objek yang mana mendapatkan peringkat 1 sampai dengan peringkat 5 .

\section{HASIL DAN PEMBAHASAN}

Akun youtube dari 5 artis youtube terkaya di Indonesia, diantaranya (kompas.com, 2021):

\section{Deddy Corbuzier}

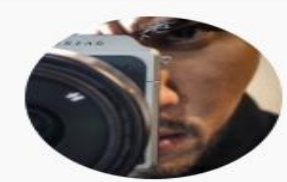




\section{Rans Entertainment}

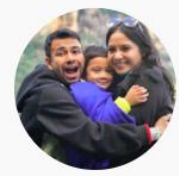

Sumber : https://www.youtube.com/c/RansEntertainment ( akses pada 22-10-2021)

\section{Baim Paula}
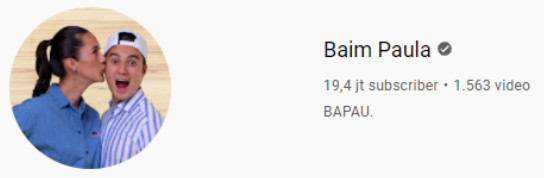

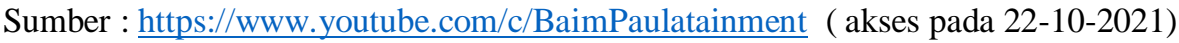

\section{Atta Halilintar}

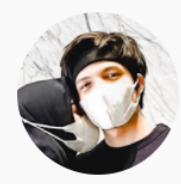

$\mathrm{AH} \odot$

28 jt subscriber $\cdot 1.433$ video

Our job is to try to make you happy : spread love and happiness Atta Halilintar Official Youtube

SUBSCRIBE

Sumber : https://www.youtube.com/c/AttaHalilintar (akses pada 22-10-2021)

\section{Ria Ricis}

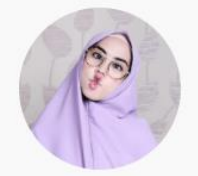

Ricis Official $\bullet$

27,2 jt subscriber $\cdot 1.539$ video

Ricis Official Real account.

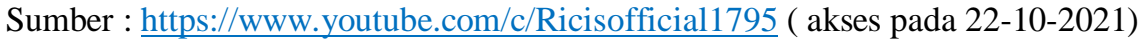

Dari kelima akun Youtube 5 Artis terkaya di Indonesia, peneliti menemukan nilai dari masingmasing variabel yang ada untuk menghitung rasio Video Comments to Subscriber dari setiap akun. Pada akun Youtube terdapat 7 variabel, diantaranya yaitu :

1. Likes

2. Subscribe

3. Subscriber 
4. Video Likes

5. Video Comments

6. Video Share

7. Video Views

Dari ketujuh variabel diatas peneliti hanya fokus untuk menemukan hasil dari 2 variabel, yaitu :

1. Video Comments

2. Subscriber

Dari kedua variabel tersebut kemudian dianalisa sehingga menemukan nilai rata-rata dari variabel video comments dan variabel subscriber. Untuk menghitung nilai rata-rata dari variabel video comments dan subscriber yaitu dengan cara mengambil minimal 10 postingan kemudian di hitung sehingga menemukan nilai rata-rata dari masing-masing variabel. Berikut merupakan tabel nilai rata-rata dari masing-masing artis di Indonesia, yaitu :

Tabel 1. Analisa Nilai Rata-Rata Nilai Variabel Video Comments dan Subscriber Akun Youtube Deddy Corbuzier

\begin{tabular}{|l|l|l|}
\hline No & $\begin{array}{l}\text { Video } \\
\text { Comment }\end{array}$ & Subscriber \\
\hline 1 & 19000 & 15.900 .000 \\
\hline 2 & 18000 & \\
\hline 3 & 5200 & \\
\hline 4 & 6200 & \\
\hline 5 & 13000 & \\
\hline 6 & 6900 & \\
\hline 7 & 8400 & \\
\hline 8 & 5200 & \\
\hline 9 & 11000 & \\
\hline 10 & 52000 & \\
\hline Total & $\mathbf{1 4 4 9 0}$ & $\mathbf{1 5 . 9 0 0 . 0 0 0}$ \\
\hline \multicolumn{3}{|c|}{ Sumber : Pengolah Data Excel }
\end{tabular}


Tabel 2. Analisa Nilai Rata-Rata Nilai Variabel Video Comments dan Subscriber Akun Youtube Rans Entetaiment

\begin{tabular}{|l|l|l|}
\hline No & $\begin{array}{l}\text { Video } \\
\text { Comment }\end{array}$ & Subscriber \\
\hline 1 & 1200 & 21.800 .000 \\
\hline 2 & 925 & \\
\hline 3 & 1400 & \\
\hline 4 & 1000 & \\
\hline 5 & 2000 & \\
\hline 6 & 674 & \\
\hline 7 & 1500 & \\
\hline 8 & 1500 & \\
\hline 9 & 1500 & \\
\hline 10 & 4900 & \\
\hline Total & 1659.9 & 21.800 .000 \\
\hline \multicolumn{3}{|c|}{ Sumber : Pengolah Data Excel } \\
\hline
\end{tabular}

Tabel 3. Analisa Nilai Rata-Rata Nilai Variabel Video Comments dan Subscriber Akun Youtube Baim Paula

\begin{tabular}{|l|l|l|}
\hline No & $\begin{array}{l}\text { Video } \\
\text { Comment }\end{array}$ & Subscriber \\
\hline 1 & 5800 & 19.400 .000 \\
\hline 2 & 7500 & \\
\hline 3 & 123000 & \\
\hline 4 & 9900 & \\
\hline 5 & 30000 & \\
\hline 6 & 8400 & \\
\hline 7 & 10000 & \\
\hline 8 & 5600 & \\
\hline 9 & 37000 & \\
\hline 10 & 1200 & \\
\hline Total & $\mathbf{2 3 8 4 0}$ & $\mathbf{1 9 . 4 0 0 . 0 0 0}$ \\
\hline \multicolumn{3}{|c|}{ Sumber : Pengolah Data Excel } \\
\hline
\end{tabular}


Tabel 4. Analisa Nilai Rata-Rata Nilai Variabel Video Comments dan Subscriber Akun Youtube Atta Halilintar

\begin{tabular}{|l|l|l|}
\hline No & $\begin{array}{l}\text { Video } \\
\text { Comment }\end{array}$ & Subscriber \\
\hline 1 & 4600 & 27.900 .000 \\
\hline 2 & 2100 & \\
\hline 3 & 3400 & \\
\hline 4 & 2400 & \\
\hline 5 & 4600 & \\
\hline 6 & 5300 & \\
\hline 7 & 5800 & \\
\hline 8 & 4700 & \\
\hline 9 & 5600 & \\
\hline 10 & 3000 & \\
\hline Total & $\mathbf{4 1 5 0}$ & $\mathbf{2 7 . 9 0 0 . 0 0 0}$ \\
\hline
\end{tabular}

Tabel 5. Analisa Nilai Rata-Rata Nilai Variabel Video Comments dan Subscriber Akun Youtube Ria Ricis

\begin{tabular}{|l|l|l|}
\hline No & $\begin{array}{l}\text { Video } \\
\text { Comment }\end{array}$ & Subscriber \\
\hline 1 & 5500 & 27.100 .000 \\
\hline 2 & 7300 & \\
\hline 3 & 6200 & \\
\hline 4 & 4600 & \\
\hline 5 & 7800 & \\
\hline 6 & 7100 & \\
\hline 7 & 10000 & \\
\hline 8 & 7100 & \\
\hline 9 & 5300 & \\
\hline 10 & 6400 & \\
\hline Total & 6730 & $\mathbf{2 7 . 1 0 0 . 0 0 0}$ \\
\hline \multicolumn{3}{|l|}{ Sumber : Pengolah Data Excel } \\
\hline
\end{tabular}

Setelah menghitung nilai rata-rata tersebut, maka akan menemukan hasil akhir nilai rata-rata dari variabel video comments dan subscriber 
Tabel6. Nilai Variabel Pada Akun Youtube 5 Artis Terkaya Di Indonesia

\begin{tabular}{|l|l|l|l|l|l|}
\hline Variabel & $\begin{array}{l}\text { Deddy } \\
\text { Corbuzier }\end{array}$ & Rans Entertainment & $\begin{array}{l}\text { Baim } \\
\text { Paula }\end{array}$ & $\begin{array}{l}\text { Atta } \\
\text { Halilintar }\end{array}$ & Ria Ricis \\
\hline $\begin{array}{l}\text { Video } \\
\text { Comment }\end{array}$ & 14490 & 1660 & 23840 & 4150 & 6730 \\
\hline Subscriber & 15900000.000 & $21,800,000$ & $19,400,000$ & $27,900,000$ & 27100000.00 \\
\hline \multicolumn{5}{|c|}{ Sumber : Pengolah Data Excel }
\end{tabular}

Pada akun Youtube terdapat 7 rasio yang relevan digunakan untuk mengukur kredibilitas pada masing-masing akun. Namun pada penelitian kali ini hanya berfokus untuk menghitung Video Comments to Subscriber Ratio. Untuk menghitung kredibilitas dari masing-masing akun Youtube setiap artis terkaya, peneliti menghitung dengan cara : variabel 1 akan dibagi dengan variabel 2, sehingga ditemukan hasil analisisa dari rasio tersebut.

Tabel 7. Hasil Perhitungan Rasio Akun Youtube

\begin{tabular}{|l|l|l|l|l|l|}
\hline Ratio & $\begin{array}{l}\text { Deddy } \\
\text { Corbuzier }\end{array}$ & $\begin{array}{l}\text { Rans } \\
\text { Entertainment }\end{array}$ & Baim Paula & $\begin{array}{l}\text { Atta } \\
\text { Halilintar }\end{array}$ & Ria Ricis \\
\hline $\begin{array}{l}\text { Video Comment \& } \\
\text { subscriber ratio }\end{array}$ & 0.00091132 & 0.00007614679 & 0.00122887 & 0.000148746 & 0.000248339 \\
\hline \multicolumn{5}{|c|}{ Sumber : Pengolah Data Excel }
\end{tabular}

Video Comments to Subscriber Ratio memiliki karakteristik yang tinggi, artinya semakin tinggi nilai yang dihasilkan maka semakin baik kredibilitas dari performa akun tersebut. Untuk memberikan peringkat pada masing-masing Artis, peneliti memberikan angka 5 kepada artis yang mendapatkan nilai tertinggi dan angka 1 untuk artis yang mendapatkan nilai terendah. Berikut merupakan tabel urutan nilai yang dihasilkan oleh masing-masing youtuber.

Tabel 8. Nilai Rasio Akun Youtube 5 Artis Terkaya Di Indonesia

\begin{tabular}{|l|l|l|l|l|l|}
\hline Ratio & $\begin{array}{l}\text { Deddy } \\
\text { Corbuzier }\end{array}$ & $\begin{array}{l}\text { Rans } \\
\text { Entertainment }\end{array}$ & Baim Paula & Atta Halilintar & Ria Ricis \\
\hline $\begin{array}{l}\text { Video Comment } \\
\text { ratio } \\
\text { rabscriber }\end{array}$ & 2 & 5 & 1 & 3 & 4 \\
\hline \multicolumn{5}{|c|}{ Sumber : Pengolah Data Excel } & \\
\hline
\end{tabular}


Dari Tabel Nilai Rasio Akun Youtuber 5 Artis terkaya di indonesia dapat simpulkan bahwa Baim Paula mendapatkan nilai tertinggi untuk rasio Video Comments to subscriber. Sedangkan akun youtube Rans Entertainment mendapatkan nilai terendah untuk rasio ini. Jadi, pada penelitian ini Baim Paula memiliki kredibilitas performa yang lebih kaya dibandingkan dengan yang lainnya.

\section{KESIMPULAN}

Tujuan dari penelitian ini adalah mengetahui kredibilitas performa dari akun youtubeTop 5 youtuber di Indonesia menggunakan Video Comments to Video Subscrib Ratio. Top 5 Youtuber tersebut diantaranya : Dedy Corbuzer, Rans Entertaiment, Baim Paula, Atta Halilintar, Ria Ricis. Dari kelima youtube tersebut dapat disimpulkan bahwa :

1. Peringkat pertama diraih oleh youtuber Baim PaulaIndonesia dengan nilai tertinggi yaitu 0.00122887

2. Peringkat kedua diraih oleh youtuber Dedy Corbuzer Indonesia dengan nilai 0.00091132

3. Peringkat ketiga diraih oleh youtuber Atta Halilintar Indonesia dengan nilai 0.000148746

4. Peringkat keempat diraih oleh youtuber Ria Ricis Indonesia dengan nilai 0.000248339

5. Peringkat kelima diraih oleh youtuber Rans Entertaiment Indonesia dengan nilai terendah yaitu 0.00007614679 


\section{DAFTAR PUSTAKA}

Chandra, E. (2018). Youtube, Citra Media Informasi Interaktif Atau Media Penyampaian Aspirasi Pribadi. Jurnal Muara Ilmu Sosial, Humaniora, Dan Seni, 1(2), 406. https://doi.org/10.24912/jmishumsen.v1i2.1035

kompas.com. (2021). Ini 5 Youtuber Indonesia Berpenghasilan Tertinggi pada Juli 2021, Deddy Corbuzier Kembali Nomor 1. Www.Kompas.Com. https://money.kompas.com/read/2021/08/01/080800526/ini-5-youtuber-indonesiaberpenghasilan-tertinggi-pada-juli-2021-deddy?page=all

Permana, I. P. H., \& Kom, S. (n.d.). Analisis Video Comments to Video Views Ratio Tiktok Pada Top 5 Vendor Smartphone di Indonesia.

Wikipedia bahasa Indonesia, ensiklopedia bebas. (2020). YouTube adalah sebuah situs web berbagi video. Www. Wikipedia.Org. https://id.wikipedia.org/wiki/YouTube

Wirga, E. W. (2016). Content Analysis on Youtube Social Media to Support Political Campaign Strategies. Jurnal Ilmiah Informatika Dan Komputer, 21(100), 14-26.

https://ejournal.gunadarma.ac.id/index.php/infokom/article/view/1716 